\title{
Marketing analytics: from practice to academia
}

\author{
Maria Petrescu $^{1}$ Anjala S. Krishen ${ }^{2}$
}

(C) Macmillan Publishers Ltd 2017

We consider business analytics an interdisciplinary and inclusive area of study which aims to be insightful and ultimately enable timely and influential firm-driven campaigns (Krishen and Petrescu 2017). The Journal of Marketing Analytics welcomes contributions from multiple disciplines of scholarly discourse as well as timely practitioner insights and ideas. We take this opportunity to underline the evolution and the importance of marketing analytics for the business world.

In Fig. 1, we present the evolution of the search popularity of "marketing analytics" on Google in the past five years. As can be seen in the figure, at a global level, the popularity of marketing analytics has increased from 50 to 100 on Google's search index (Google 2017). Interest has also been higher for queries, such as "analytics in marketing" and "digital marketing analytics", showing a propensity for analyzing online marketing activity.

Moreover, the search popularity of "marketing analytics" on Google is not confined to one country but instead has a global characteristic, as shown in Fig. 2. The interest in marketing analytics is, not surprisingly, the highest in India, one of the top providers of digital services on the international market, followed by the United States. Other Western countries follow close in their Google searches for information relating to marketing analytics.

Maria Petrescu

mpetresc@nova.edu

Anjala S. Krishen

anjala.krishen@unlv.edu

1 Nova Southeastern University, Fort Lauderdale, FL, USA

2 University of Nevada, Las Vegas, NV, USA
These findings are correlated with the situation in the business world. Top business consulting and digital solutions companies offer marketing analytics services to their clients. Innovative organizations such as Accenture, SAS, McKinsey, Salesforce, Hubspot, and Marketo provide analytics solutions that include big data, sales, service, B2B

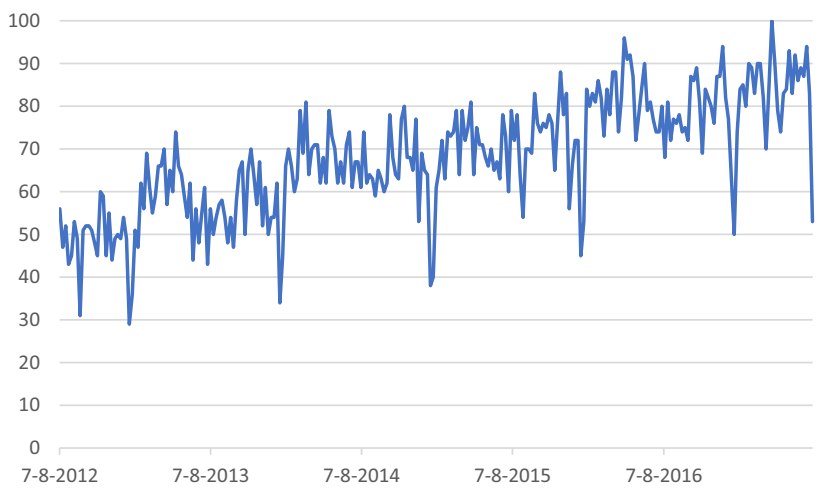

Fig. 1 Google search index for "marketing analytics"

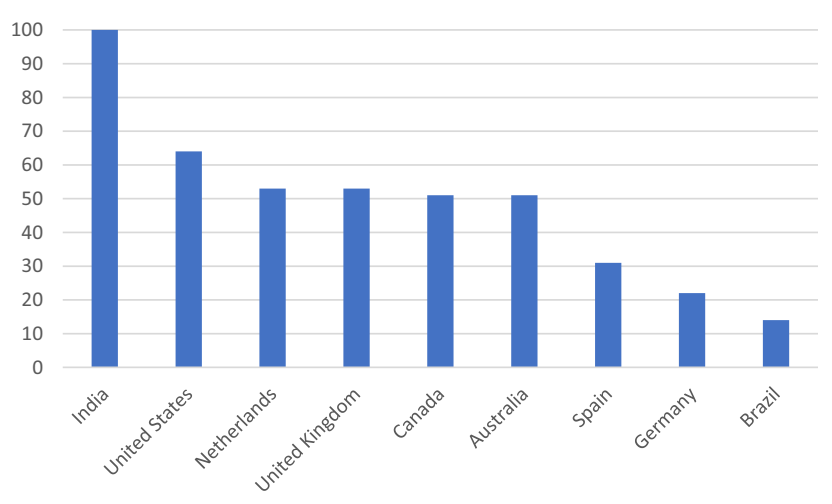

Fig. 2 Global distribution of searches 
market analytics, full market mix modeling, and causal forecasting. These services allow companies to analyze past performances and real-time evolutions, as well as make data-driven predictions.

The academic world has adapted to the increased demand for marketing analytics as well. Besides different specializations offered in this field, some colleges are already promoting full degrees in the domain of marketing analytics. For example, New York University offers a BS degree in Marketing Analytics, while universities such as Tilburg University, the University of Southampton and the University of Maryland offer master degrees in Marketing Analytics.

Considering the pervasive nature and importance of this field, we encourage submissions that contribute to business research, are of interest to academics, and especially treat topics of concern for business practitioners from the domain of marketing analytics. Subjects from the areas of customer analysis, big data mining and text mining, socialnetwork analytics, data science, market forecasting, web analytics and CRM are always welcome.

\section{References}

Google. (2017). Marketing Analytics. Retrieved from https://trends. google.com/trends/explore?q=marketing\%20analytics.

Krishen, A.S., and M. Petrescu. 2017. The world of analytics: Interdisciplinary, inclusive, insightful, and influential. Journal of Marketing Analytics 5: 1. doi:10.1057/s41270-017-0016-4.

Dr. Maria Petrescu is an Associate Professor of Marketing at Nova Southeastern University. Her research interests include digital marketing, word-of-mouth, and marketing analytics, as well as cross cultural studies. She has published in numerous business journals, including the Journal of Retailing and Consumer Services, the Journal of Product and Brand Management and the Journal of Marketing Analytics.

Dr. Anjala S. Krishen has a Ph.D. from Virginia Tech and has worked full-time for 13 years in companies including Oracle Corporation, American Electric Power, and Enerwise Global Technologies. In 2007, she joined University of Nevada, Las Vegas, where she is an Associate Professor of Marketing \& International Business in the Lee Business School. Her interdisciplinary research interests include areas within decision making in rich environments, including heuristics and choice set design, e-marketing and social networking, and database marketing. 